\title{
Studies on dielectric hysteresis of ferroelectric sodium vanadate, rubidium vanadate, cesium vanadate and their solid solutions
}

\author{
V V PATIL, A P KASHID ${ }^{\dagger}$ and S H CHAVAN* \\ Department of Physics, Main Rajaram Jr. College, Kolhapur 416 002, India \\ + Warna Mahavidyalaya, Warananagar 416113, India \\ *Department of Physics, Shivaji University, Kolhapur 416004 , India \\ MS received 12 October 1988; revised 29 April 1989
}

\begin{abstract}
The dielectric hysteresis property of sodium vanadate, rubidium vanadate, cesium vanadate and their solid solutions has been studied in the temperature range rovering their transition points. The hysteresis loop method is used for coercive field measurements. It was observed that the coercive field decreases with increasing temperature, and that it also decreases with increasing sodium concentration in the solid solutions (sodium-rubidium) vanadate and (sodium-cesium) vanadate.
\end{abstract}

Keywords. Ferroelectrics; Curie temperature; hysteresis; coercive field.

\section{Introduction}

The basic characteristic of a ferroelectric material is that it possesses a hysteresis loop. The hysteresis loop representation permits the measurement of the spontaneous polarization and the coercive field of ferroelectrics. The coercive field of a ferroelectric crystal is defined as the external field required for transition from a metastable state to a stable one through domain reversal. The dependence of the ferroelectric coercive field upon the thickness of a single crystal of $\mathrm{BaTiO}_{3}$ was reported by Weider (1955) and an interpretation of thickness dependence was provided by Brezina and Janovec (1964). The ferroelectric properties of $\mathrm{NaVO}_{3}$ below $380^{\circ} \mathrm{C}$ were first studied by Sawada and Nomura (1951). The variation of a coercive field with the frequency and amplitude of the applied field was studied by Landaur et al (1956). A theoretical treatment based on the assumption that the coercive field is determined by the velocity of the forward growth of the domain was given by Abe (1960). Chavan and Suryavanshi (1985) reported that $\mathrm{KVC}_{3}$ is ferroelectric below $320^{\circ} \mathrm{C}$. The pyroelectric and dielectric properties for sodium vanadate, potassium vanadate, lithium vanadate and their solid solutions were studied by Patil et al (1988).

The aim of our present paper is to study the dielectric hysteresis of $\mathrm{NaVO}_{3}$, $\mathrm{RbVO}_{3}, \mathrm{CsVO}_{3}$ and their solid solutions $\left(\mathrm{Na}_{x}-\mathrm{Rb}_{1-x}\right) \mathrm{VO}_{3},\left(\mathrm{Na}_{x}-\mathrm{Cs}_{1-x}\right) \mathrm{VO}_{3}$ and to report the variation of the coercive field with temperature, and also to determine the Curie temperatures of these materials.

\section{Experimental}

Sodium vanadate ceramics were prepared from a mixture of sodium carbonate and vanadium pentoxide with 1:1 molar proportions and heated in a platinum crucible

\footnotetext{
*For correspondence.
} 
in a globar furnace up to $750^{\circ} \mathrm{C}$ for $4 \mathrm{~h} . \mathrm{RbVO}_{3}$ and $\mathrm{CsVO}_{3}$ ceramics were similarly prepared. Solid solutions of $\left(\mathrm{Na}_{x}-\mathrm{Rb}_{1-x}\right) \mathrm{VO}_{3}$ were prepared from their respective vanadates with molar proportions $(x=0.75,0.50,0.25)$ and heated in a globar furnace at $750^{\circ} \mathrm{C}$ for $4 \mathrm{~h}$ in a platinum crucible. Solid solutions of $\left(\mathrm{Na}_{x}-\mathrm{Cs}_{1-x}\right) \mathrm{VO}_{3}$ $(x=0.75,0.50,0.25)$ were prepared by the same method.

The formation of the solid solutions was confirmed by XRD chart. Pellets of these solid solutions having a thickness of about $1 \mathrm{~mm}$ and $\mathrm{a}$ dia $\approx 1 \mathrm{~cm}$ were prepared under a pressure of 5 tonnes by using hydraulic press. The test samples were made by sintering these pellets at $450^{\circ} \mathrm{C}$ for $3 \mathrm{~h}$. The two end faces of these test samples were rendered conducting by applying silver paste and were placed in a sample-holder, with stainless steel electrodes, fabricated in our laboratory.

The experimental set-up consisted of an electrically heated furnace, a digital micro-voltmeter and a modified form of the Sawyer and Tower (1930) circuit. The sample was slowly heated inside a furnace. A hysteresis loop was observed very easily on the oscilloscope screen. The voltage across the plate was $1 \mathrm{kV} / \mathrm{cm}$ and the frequency of the applied field was $50 \mathrm{~Hz}$. The half-width of the hysteresis loop enables the measurement of the coercive field at various temperatures by calibrating the screen of an oscilloscope. It was found that the accuracy in the measurement of $E_{c}$ and $T_{c}$ was 1.5 and $0.5 \%$ respectively. The overall reproducibility in the measurement of $E_{c}$ and $T_{c}$ was 2 and $1 \%$ respectively.

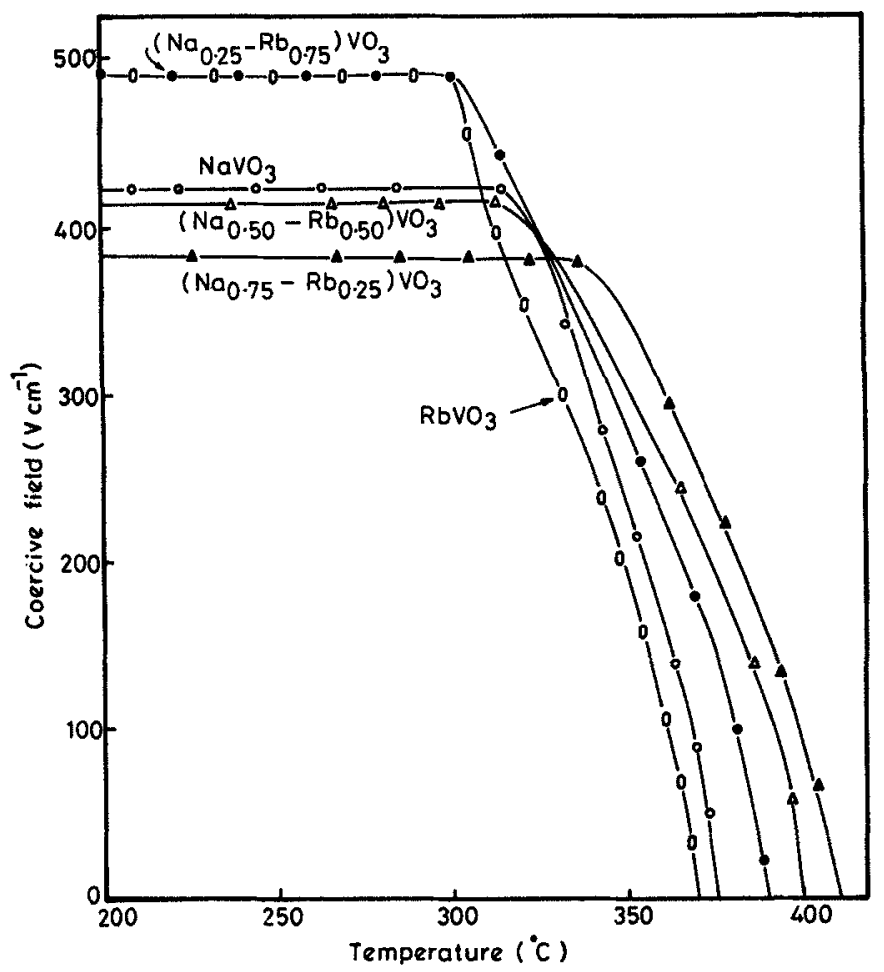

Figure 1. Variation of coercive field with temperature for $\mathrm{NaVO}_{3}, \mathrm{RbVO}_{3}$ and $\left(\mathrm{Na}_{x}-\right.$ $\left.\mathrm{Rb}_{1-x}\right) \mathrm{VO}_{3}$ measured with a field of $1 \mathrm{kV} / \mathrm{cm}$ at $50 \mathrm{~Hz}$. 


\section{Results and discussion}

The variation of the coercive field with temperature for $\mathrm{NaVO}_{3}, \mathrm{RbVO}_{3}$ and $\mathrm{CsVO}_{3}$ as shown in figures 1 and 2 reveals that the coercive field strongly depends upon the temperature. It decreases with increase of temperature. The vanishing of the hysteresis loop on an oscilloscope by using a modified form of the Sawyer and Tower circuit gives the Curie temperatures for the ferroelectric materials $\mathrm{NaVO}_{3}$, $\mathrm{RbVO}_{3}$ and $\mathrm{CsVO}_{3}$ at 375,370 and $400^{\circ} \mathrm{C}$ respectively. These Curie temperatures are in good agreement with those reported previously by Patil et al (1988).

It is observed that the coercive field for different molar proportions of $\left(\mathrm{Na}_{x}-\mathrm{Rb}_{1-x}\right) \mathrm{VO}_{3}$ vanishes at 390,400 and $410^{\circ} \mathrm{C}$, and so also for different molar proportions of $\left(\mathrm{Na}_{x}-\mathrm{Cs}_{1-x}\right) \mathrm{VO}_{3}$ at 405,410 and $415^{\circ} \mathrm{C}$, indicating that these are the Curie temperatures of the respective solid solutions shown in figures 1 and 2 . It is seen that the Curie temperatures increase with Na concentration. Figures 1 and 2 also show that the coercive field decreases as $\mathrm{Na}$ concentration in the solid solution increases.

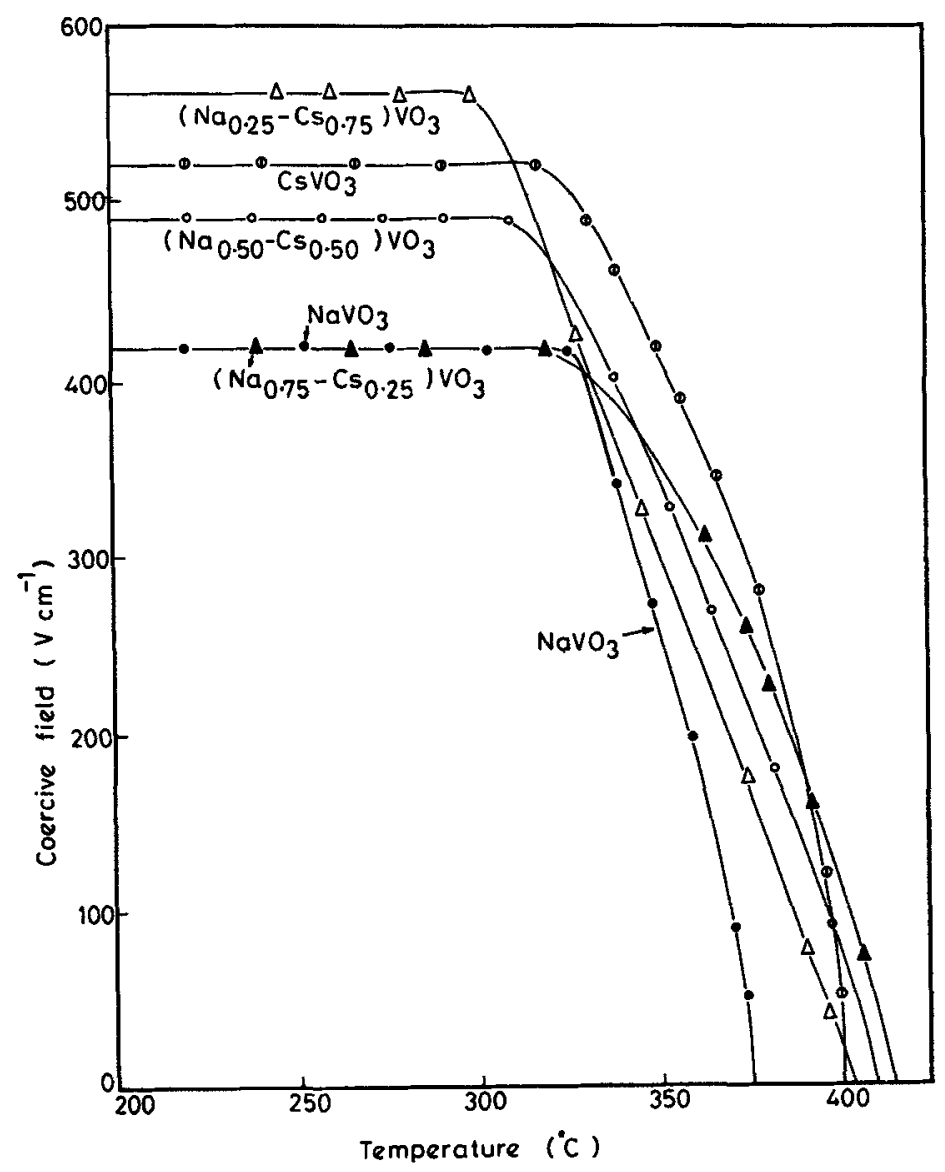

Figure 2. Variation of coercive field with temperature for $\mathrm{CsVO}_{3}$ and $\left(\mathrm{Na}_{x}-\mathrm{Cs}_{1-x}\right) \mathrm{VO}_{3}$ measured with a field of $1 \mathrm{kV} / \mathrm{cm}$ at $50 \mathrm{~Hz}$. 
Table 1. Maximum values of cocrcive field of materials and their Curie temperatures.

\begin{tabular}{lcc}
\hline Material & $\begin{array}{c}\text { Coercive field } \\
(\mathrm{V} / \mathrm{cm})\end{array}$ & $\begin{array}{c}\text { Curie temperature } \\
\left({ }^{\circ} \mathrm{C}\right)\end{array}$ \\
\hline $\mathrm{NaVO}_{3}$ & 420 & 375 \\
$\mathrm{RbVO}_{3}$ & 490 & 370 \\
$\mathrm{CsVO}_{3}$ & 520 & 400 \\
$\left(\mathrm{Na}_{0.25}-\mathrm{Rb}_{0.75}\right) \mathrm{VO}_{3}$ & 490 & 390 \\
$\left(\mathrm{Na}_{0.50}-\mathrm{Rb}_{0.50}\right) \mathrm{VO}_{3}$ & 420 & 400 \\
$\left(\mathrm{Na}_{0.75}-\mathrm{Rb}_{0.25}\right) \mathrm{VO}_{3}$ & 385 & 410 \\
$\left(\mathrm{Na}_{0.25}-\mathrm{Cs}_{0.75}\right) \mathrm{VO}_{3}$ & 560 & 405 \\
$\left(\mathrm{Na}_{0.50}-\mathrm{Cs}_{0.50}\right) \mathrm{VO}_{3}$ & 490 & 410 \\
$\left(\mathrm{Na}_{\mathbf{0} .75}-\mathrm{Cs}_{0.25}\right) \mathrm{VO}_{3}$ & 420 & 415 \\
\hline
\end{tabular}

The peak values of the coercive field for $\mathrm{NaVO}_{3}, \mathrm{RbVO}_{3}, \mathrm{CsVO}_{3}$ and their solid solutions $\left(\mathrm{Na}_{x}-\mathrm{Rb}_{1-x}\right) \mathrm{VO}_{3},\left(\mathrm{Na}_{x}-\mathrm{Cs}_{1-x}\right) \mathrm{VO}_{3}(x=0.25,0.50,0.75)$ are summarized in table 1 .

\section{Conclusions}

(i) The coercive field decreases with increase in temperature and vanishes at the Curie temperature, for the ferroelectrics $\mathrm{NaVO}_{3}, \mathrm{RbVO}_{3}$ and $\mathrm{CsVO}_{3}$, and their solid solutions.

(ii) In solid solutions, the coercive field decreases with increase in Na concentration.

(iii) The Curie temperatures increase with increase in $\mathrm{Na}$ concentration in the solid solutions $\left(\mathrm{Na}_{x}-\mathrm{Rb}_{1-x}\right) \mathrm{VO}_{3}$ and $\left(\mathrm{Na}_{x}-\mathrm{Cs}_{1-x}\right) \mathrm{VO}_{3}$.

\section{References}

Abe R 1960 J. Phys. Soc. Jpn. 15795

Brezina B and Janovec V 1964 Czekh J. Phys. B14 44

Chavan S H and Suryavanshi 1985 Indian J. Phys. A59 555

Landauer R. Young D R and Droughard M E 1956 J. Appl. Phys. 27752

Patil T A, Jamadar V M and Chavan S H 1988a Indian J. Phys. A62 341

Patil T A, Jamadar V M and Chavan S H 1988b Indian J. Pure Appl. Phys. 26456

Sawada S and Nomura S 1951 J. Phys. Soc. Jpn. 6192

Sawyer C B and Tower C H 1930 Phys. Rev. 35269

Weider H H 1955 J. Appl. Phys. 261479 